\title{
Long-chain polyene status of preterm infants with regard to the fatty acid composition of their diet: comparison between absolute and relative fatty acid levels in plasma and erythrocyte phospholipids
}

\author{
BY MAGRITHA M. H.P. FOREMAN-VAN DRONGELEN ${ }^{1}$, \\ ADRIANA C. V. HOUWELINGEN ${ }^{1}$, ARNOLD D. M. KESTER ${ }^{2}$, \\ ANDRÉ E. P. DE JONG ${ }^{3}$, CARLOS E. BLANCO ${ }^{4}$, TOM H. M. HASAART ${ }^{5}$ \\ AND GERARD HORNSTRA ${ }^{1}$ \\ Departments of ${ }^{1}$ Human Biology and ${ }^{2}$ Methodology and Statistics, University of Limburg, \\ Universiteitssingel 50, 6229 ER Maastricht, The Netherlands \\ ${ }^{3}$ Analytical Biochemical Laboratory, WA Scholtenstraat 7, 9403 AJ Assen, The Netherlands \\ Departments of ${ }^{4}$ Neonatology and ${ }^{5}$ Obstetrics and Gynaecology, University Hospital Maastricht, \\ P Debyelaan 25, 6229 HX Maastricht, The Netherlands
}

(Received 30 September 1993 - Revised 23 June 1994 - Accepted 24 June 1994)

\begin{abstract}
The long-chain polyene (LCP) status of thirty-nine premature infants (birth weight $<1800 \mathrm{~g}$ ) was evaluated. Twenty-seven infants were fed on an artificial formula, twelve received their own mother's breast milk. Fatty acid compositions of both plasma and erythrocyte (RBC) phospholipids (PL) were determined in umbilical venous blood and in weekly postnatal blood samples until the 28th day of life. Individual fatty acid levels were expressed as absolute quantities (mg fatty acid/l plasma or RBC suspension) and as relative (mg/100 mg total fatty acids) values. The changes with time in the absolute values for 22:6n-3 and 20:4n-6 in plasma were strikingly different from those of the relative values for these fatty acids. In plasma PL the inter-group differences in the absolute postnatal values for 22:6n-3 $(P<0.0005)$ and 20:4n-6 $(P<0.05)$ and the relative values for $22: 6 n-3(P<0.02)$ were significant, with lower fatty acid values in the formula-fed infants. In RBC PL, no significant inter-group differences in the postnatal 22:6n-3 and 20:4n-6 values were found. Based on the assumption that it is desirable for formula-fed infants to achieve postnatal plasma LCP values at least comparable with those found in infants fed on human milk, the findings of the present study indicate that both $n-3$ and $n-6$ LCP should be added to preterm infant formulas. Moreover, the additional importance of absolute fatty acid levels was demonstrated, although analytical procedures need to be standardized to enable effective comparison of results from different research groups.
\end{abstract}

Docosahexaenoic acid: Arachidonic acid: Human milk: Formula milk: Preterm infant

The demand of the fetal and neonatal brain for docosahexaenoic acid (cervonic acid; $22: 6 n-3)$ and arachidonic acid (20:4n-6) shows a substantial increase during the last trimester of pregnancy and the first months of postnatal life (Clandinin et al. 1980a,b). Therefore, an adequate supply of these long-chain polyenes (LCP; essential fatty acids (EFA) with a chain length of $\mathrm{C}_{20}$ or more), which are two of the most abundant structural fatty acids in the brain (Svennerholm, 1968; Sastry, 1985) as well as in the retina (Fliesler \& Anderson, 1983), is required both pre- and postnatally.

Conventional artificial formulas, unlike human milk, contain only trace amounts of 22:6n-3, 20:4n-6 and other LCP (Jensen et al. 1978, 1992; Lammi-Keefe \& Jensen, 1984). 
Substantial amounts of the parent EFA linoleic acid $(18: 2 n-6)$ and $\alpha$-linolenic acid $(18: 3 n-3)$ are present in artificial formulas (Jensen $e t$ al. 1978, 1992; Lammi-Keefe \& Jensen, 1984). However, the desaturase capacity of newborn infants is probably too limited to guarantee an adequate supply of $n-3$ and $n-6$ LCP solely through metabolic conversion of these two fatty acids (Clandinin et al. $1980 \mathrm{~b}$; Chambaz et al. 1985). Since neonatal LCP stores, particularly those of preterm newborns, are also very limited (Clandinin et al. $1980 \mathrm{~b}$, 1981), the use of conventional formulas could result in a considerable deterioration of the LCP status after birth, especially in children who are born prematurely. The occurrence of such a deterioration has been reported in a number of studies (Carlson et al. 1986; Pita et al. 1988; Koletzko et al. 1989; Clandinin et al. 1992). Further investigations have demonstrated that adding $n-3$ or $n-3$ and $n-6$ LCP to the artificial formulas results in a substantial reduction in this deterioration (Carlson et al. 1987, 1991; Koletzko et al. 1989; Clandinin et al. 1992). The conclusions of the majority of these studies were based on relative fatty acid values $(\mathrm{mg} / 100 \mathrm{mg}$ or $\mathrm{mol} / 100 \mathrm{~mol}$ total fatty acids) for the plasma (Koletzko et al. 1989) or erythrocyte (RBC) lipid fraction (Carlson et al. 1986, 1987; Pita et al. 1988). The impression obtained from relative values, however, can be strikingly different from that obtained from absolute levels. For example, while relative values for 20:4n-6 and 22:6n-3 are higher in cord plasma phospholipids (PL) than in maternal plasma, absolute quantities ( $\mathrm{mg} / \mathrm{l}$ plasma) are significantly lower. This is due to a considerably lower PL concentration in cord blood (Hornstra, 1993). In addition, when comparing preterm infants fed on an artificial formula with preterm infants receiving fatfree parenteral nutrition, a larger increase in $20: 3 n-9: 20: 4 n-6$ values (commonly used as biochemical evidence of EFA deficiency) between birth and the 3rd day of life was observed in the latter group. This was not associated with lower absolute levels of $n-3$ and $n-6 \mathrm{LCP}$ in this group (Foote et al. 1991). Thus, absolute fatty acid values may very well provide additional information on the LCP status of preterm infants, as influenced by their nutritional EFA intake.

To evaluate this assumption the postnatal pattern of the LCP status, with special emphasis on $22: 6 n-3$ and $20: 4 n-6$, of premature infants fed on conventional artificial formulas was compared with that of preterm infants receiving their own mother's breast milk. The LCP patterns of both plasma and RBC PL were studied. PL are structural lipids which are the richest source of polyunsaturated fatty acids (PUFA), including LCP. In addition, changes in PUFA profile are most pronounced in PL (Holman, 1986). The fatty acid values were expressed as absolute quantities ( $\mathrm{mg} / \mathrm{l}$ plasma or RBC suspension) and as relative values $(\mathrm{mg} / 100 \mathrm{mg}$ total fatty acids).

\section{SUBJECTS AND METHODS}

\section{Experimental design}

Subjects. Thirty-nine infants, born before the 37th week of gestation and free from metabolic disease and major congenital malformations, participated in the study. Gestational age was confirmed by menstrual history and early ultrasound dating, and by Dubowitz score (Dubowitz et al. 1970) if the former information was missing or doubtful. The infants had to have a birth weight of $1800 \mathrm{~g}$ or less, because larger infants were likely to be discharged before the intended duration of the study (4 weeks). Immediately after delivery (day 0 ), approximately $3 \mathrm{ml}$ umbilical venous blood was collected. Thereafter, the EFA status of the infants was monitored until they were discharged or transferred to a nonparticipating hospital. For this purpose, a weekly sample of approximately $0.5 \mathrm{ml}$ capillary or venous blood was collected in conjunction with a diagnostic puncture. These diagnostic punctures were part of the routine clinical monitoring of all preterm infants at the 
Table 1. Clinical and nutritional characteristics of preterm infants fed on their own mother's milk (human-milk (HM) group) and those fed on artificial-formula milk (artificial-formula $(A F)$ group)

(Values are medians and interquartile ranges, except where indicated)

\begin{tabular}{|c|c|c|c|c|}
\hline & \multicolumn{2}{|c|}{ HM group ( $n$ 12) } & \multicolumn{2}{|c|}{ AF group ( $n 27)$} \\
\hline & Median & Range & Median & Range \\
\hline Maternal age (years) & $29 \cdot 0$ & $28 \cdot 0-32 \cdot 0$ & $28 \cdot 0$ & $24 \cdot 5-30 \cdot 5$ \\
\hline Primipara & $7(58 \cdot 3 \%)^{*}$ & & $14(51.9 \%)^{*}$ & \\
\hline Gestational age (weeks) & $31 \cdot 2$ & $29 \cdot 5-34 \cdot 1$ & $30 \cdot 5$ & $29 \cdot 0-34 \cdot 3$ \\
\hline Birth wt $(\mathrm{g})$ & 1415 & $1065-1615$ & 1400 & $1120-1720$ \\
\hline Daily wt gain (days $0-28 ; \mathrm{g} / \mathrm{kg}$ ) & $10 \cdot 13$ & $7 \cdot 42-12 \cdot 86$ & 12.07 & $9 \cdot 25-14 \cdot 74$ \\
\hline $\mathrm{SGA}(\mathrm{P}<2.3) \dagger$ & $3(25 \%)^{*}$ & & $5(18.5 \%)^{*}$ & \\
\hline \multicolumn{5}{|l|}{ Intravenous: } \\
\hline Lipids $(\mathrm{kJ} / \mathrm{kg}$ per $\mathrm{d})$ & $23 \cdot 77$ & $15 \cdot 36-52 \cdot 22$ & $16 \cdot 23$ & $6 \cdot 65-31.59$ \\
\hline Plasma (ml): Mean & $10 \cdot 44$ & & $21 \cdot 81$ & \\
\hline SE & $3 \cdot 58$ & & $6 \cdot 22$ & \\
\hline $\mathrm{RBC}(\mathrm{ml})$ : Mean & $14 \cdot 45$ & & $27 \cdot 79$ & \\
\hline SE & 5.98 & & 6.74 & \\
\hline Enteral intake $(\mathrm{kJ} / \mathrm{kg}$ per $\mathrm{d})$ & $297 \cdot 8$ & $222 \cdot 2-415 \cdot 7$ & $261 \cdot 1$ & $240 \cdot 1-367 \cdot 6$ \\
\hline Age at first enteral intake (d) & $4 \cdot 0$ & $3 \cdot 0-6 \cdot 5$ & 60 & $3 \cdot 0-8.0$ \\
\hline Age at full enteral intake (d) & $14 \cdot 5$ & $11 \cdot 0-19 \cdot 50$ & $13 \cdot 0$ & $9 \cdot 00-22.00$ \\
\hline Ventilatory support $\ddagger$ (d): Mean & 3.0 & & 5.0 & \\
\hline SE & $1 \cdot 5$ & & $2 \cdot 0$ & \\
\hline Ventilatory support $¥>24 \mathrm{~h}$ & $6(50 \cdot 0 \%)$ & & $11(44 \cdot 8 \%)$ & \\
\hline BPD & $0(0.0 \%)^{*}$ & & $2(7.4 \%)^{*}$ & \\
\hline Sepsis & $4(33 \cdot 3 \%)^{*}$ & & $4(14.8 \%)^{*}$ & \\
\hline IVH & $0(0.0 \%)^{*}$ & & $4(14.8 \%)^{*}$ & \\
\hline
\end{tabular}

SGA, small-for-gestational age; P, birth-weight percentile; RBC, erythrocytes; BPD, bronchopulmonary dysplasia; IVH, intraventricular haemorrhage.

* No. of subjects and percentage of total no. of subjects in parentheses.

† Infants were small-for-gestational age with a birth weight below the $2 \cdot 3$ rd percentile of the Amsterdam growth charts (Kloosterman, 1983).

\& Ventilatory support included mechanical ventilation and continuous positive airway pressure.

neonatology ward and were done mainly to evaluate the electrolyte status, blood glucose, triacylglycerol and amino acid levels and the $\mathrm{RBC}$ and leucocyte count. Because frequent oral feeds are given (every 2-3 h) to preterm infants, blood samples could not be collected after fasting, but were taken between 1 and $1.5 \mathrm{~h}$ after a feed. The study was approved by the Medical Ethics Committee of the University Hospital of Maastricht and written informed consent was obtained from one or both parents.

The children were admitted to the neonatal care unit, where they were cared for in an incubator until being transferred to a crib at a weight of $2000 \mathrm{~g}$. If the infants were in satisfactory clinical condition they were discharged at a weight of $2400 \mathrm{~g}$. Clinical care was provided by the attending neonatologists and resident physicians according to current standards; this included respiratory support through continuous positive airway pressure or intubation and mechanical ventilation, if necessary. Careful records of these and other clinical details were made. Weight was recorded daily.

Some infants received intravenous $\mathrm{RBC}$ and plasma infusions at different times during the treatment. Since these preparations contain significant amounts of $22: 6 n-3$ and $20: 4 n-$ 6 , the time of infusion and the amount administered were recorded carefully. Furthermore, 
neonatal blood samples were always collected $24 \mathrm{~h}$ or more after an infusion. The most important clinical and nutritional characteristics of the study groups are shown in Table 1. No significant differences were found for any of these features.

Diets. Until the infants were on full enteral feeding they received parenteral nutrition containing the appropriate amounts of carbohydrates $(210 \mathrm{~kJ} / \mathrm{kg}$ per d), amino acids $(50 \mathrm{~kJ} / \mathrm{kg}$ per d), vitamins, and minerals. In addition, up to $95 \mathrm{~kJ} / \mathrm{kg}$ per $\mathrm{d}$ of intravenous lipids (Intralipid ${ }^{\circledR} 10 \%$ and $20 \%$, Vitalipid ${ }^{\circledR}$ ) were given as a source of fat. Since these preparations proved to contain up to 0.2 and $0.3 \mathrm{mg}$ of $22: 6 n-3$ and $20: 4 n-6 / 100 \mathrm{mg}$ total fatty acids respectively (M. M. H. P. Foreman-van Drongelen, unpublished results), the amounts given were registered.

When the infants were able to tolerate enteral feedings they were given (initially expressed) preterm human milk obtained from their own mothers, in case they decided to breast-feed. These infants $(n 12)$ formed the human-milk group. Incidentally, $50 \mathrm{~g}$ premature formula powder (preterm formula A; Table 2)/1 preterm human milk was added to increase an infant's energy intake, in case there was no satisfactory growth on breast milk alone. When the mother was unable to express enough milk an appropriate formula was supplied to cover the nutritional demand of her child. If the intake of artificial formula exceeded $250 \mathrm{ml} / 1$ total enteral intake the infant was excluded from the human-milk group. If the mother did not wish to provide breast milk the infant was introduced to enteral feeding with a special premature-infant formula (A or B; Table 2) used on the ward. At a weight of $2100-2200 \mathrm{~g}$ the premature-infant formula was replaced by a regular infant formula ( $\mathrm{C}$ or $\mathrm{D}$; Table 2). All formulas given were commercialy available. These infants ( $n$ 27), who did not receive any human milk, formed the artificial-formula group. The discrepany between the number of subjects in the human-milk group ( $n 12)$ and the formula group ( $n$ 27) reflects the general distribution of the type of oral nutrition given within the preterm population at the Neonatology Department in Maastricht.

Enteral feeds were administered through a nasal tube until the infant was able to drink from a bottle or his or her mother's breast. The majority of the infants received their first enteral intake during the first week of life and they were on full enteral feeding of $420-500 \mathrm{~kJ} / \mathrm{kg}$ per $\mathrm{d}$ at, on average, the 14 th day of life (Table 1 ).

To obtain accurate information on the dietary EFA intake of the participating infants a $1 \mathrm{ml}$ sample for fatty acid analysis was taken from every bottle of expressed milk after homogenization. Furthermore, the volumes consumed from every bottle of expressed breast milk and the volumes and types of formula given were recorded carefully by the nursing personnel.

\section{Laboratory analysis}

Blood samples. These were collected in tubes containing EDTA to prevent coagulation. The plasma was separated from the $\mathrm{RBC}$ by centrifugation. $\mathrm{RBC}$ were washed twice with EDTA-containing saline $\left(\mathrm{Na}_{2}\right.$ EDTA. $\left.2 \mathrm{H}_{2} \mathrm{O}\right) 28.64 \mathrm{~g}, \mathrm{NaCl} 7.00 \mathrm{~g}, \mathrm{H}_{2} \mathrm{O} 1000.0 \mathrm{ml}$ ). The tubes containing plasma or $\mathrm{RBC}$ suspension were closed under a stream of $\mathrm{N}_{2}$ to prevent oxidation and stored at $-80^{\circ}$ until analysed.

Milk samples. Individual human-milk samples were collected in fat-free glass tubes, containing $2 \mu \mathrm{l}$ of the antioxidant butylhydroxytoluene $(500 \mathrm{mg} / 1$ methanol), after which they were stored at $-80^{\circ}$.

Based on the volumes consumed from the corresponding bottles of expressed milk, appropriate amounts of the individual samples were pooled into one representative weekly sample which was used for fatty acid analysis. Pooling of samples was carried out according to the guidelines of the International Dairy Federation (1987) for the preparation of a test sample. The weekly samples were stored at $-80^{\circ}$ until analysed for fatty acids. 
Fatty acid analysis. To ensure uniformity of analytical conditions, all blood samples from a given study subject were analysed simultaneously as soon as the subject had completed the study. The same procedure was applied to the weekly human-milk samples.

At the start of the analysis, 31.0 $\mathrm{g}$ 1,2-dinonadecanoyl phosphatidylcholine (19:0 PC) was added to every sample as an internal standard. Total lipid extracts of plasma and RBC were prepared using a modified Folch extraction: $50-100 \mu 1$ samples of plasma or RBC suspension were added to $3 \mathrm{ml}$ methanol-chloroform $(1: 2, \mathrm{v} / \mathrm{v}$; Folch et al. 1957; Hoving et al. 1988). The PL fraction was isolated by solid-phase extraction on an aminopropylsilica column (Kaluzny et al. 1985). The PL were saponified and the fatty acids converted to the corresponding methyl esters by reaction with $\mathrm{BF}_{3}$ in methanol $(140 \mathrm{~g} / 1)$ at $100^{\circ}$ for 1 h (Morrisson \& Smith, 1964).

For trans-esterification of fatty acids in human milk and artificial formula, $100 \mu 1$ samples of milk were added to $2 \mathrm{ml}$ methanol-hydrochloric acid $(5: 1, \mathrm{v} / \mathrm{v})$ and heated at $90^{\circ}$ for $4 \mathrm{~h}$. After cooling, the samples were extracted with $1 \mathrm{ml}$ iso-octane (van der Steege et al. 1987).

The samples were analysed using capillary GLC with flame-ionization detection, on a $50 \mathrm{~m} \times 0.25 \mathrm{~mm}$ CP-Sil $5 \mathrm{CB}$, film thickness $0.12 \mu \mathrm{m}$ (Chrompack, Middelburg, The Netherlands) column, using $\mathrm{N}_{2}$ as the carrier gas. The analyses were performed using temperature programming which had been optimized with a reference mixture containing most of the fatty acid methyl esters (FAME) of interest. The standard mixture was also used to identify the FAME corresponding to the various peaks. Fatty acid levels present in the PL fraction (for plasma and RBC samples) or in the total lipid fraction (for milk samples) were quantified on the basis of the amount of 19:0 internal standard FAME recovered.

The day-to-day reproducibility of the analytical method, as indicated by the coefficient of variation of the levels (mmol/1) measured for the main fatty acids of interest, varied between $2 \cdot 1$ and $3.7 \%$ in seventeen plasma PL samples and between 3.7 and $6.3 \%$ in nine RBC PL samples (de Jong et al. 1993).

\section{Statistical analysis}

Study-size calculations were based on the results of Koletzko et al. (1989) using the exact calculations provided by Systat's Design program (Dallal, 1988). With two groups of ten infants an inter-group difference of $0.5 \%$ for $22: 6 n-3$ or $1.0 \%$ for $20: 4 n-6$ in plasma PL would be detected with $90 \%$ power.

For practical reasons, not all blood samples were taken on exactly the days intended. Since we wanted to analyse values at 1 -week intervals, the fatty acid values were estimated at days 7,14, 21 and 28 by linear interpolation between the days where blood had been sampled. The time intervals between the collection of individual neonatal blood samples varied from 5 to $15 \mathrm{~d}$, and, on average, less than one of the ideally-required five punctures was missing. Unless mentioned otherwise, all values are presented as medians and the upper and lower limits of the interquartile range.

Since group membership (human milk or artificial formula) was not obtained by randomization but by maternal choice, analyses were done essentially on postnatal changes, to correct for possible inter-group differences for values at day 0 . The interpretation of the results was similar when adjustment for values at day 0 was made using regression analysis.

The two LCP of primary interest, $22: 6 n-3$ and $20: 4 n-6$, were analysed most extensively. Since after the interpolation procedure there were remaining missing observations, a repeated-measures analysis-of-variance model was used which uses all available data 
(Jennrich \& Schluchter, 1986). This technique is available in the BMDP package (Dixon et al. 1990). It should be noted that in conventional repeated-measures analysis all patients with incomplete data have to be omitted from the analysis. When pooled over the sampling days the normality condition was reasonably satisfied, except for the absolute fatty acid amounts in plasma, where a log transformation was needed. Outcomes of this analysis are obtained as Wald tests for each considered factor: time, group and time $\times$ group. The first term (time) tests whether there are differences between days for both groups together, the second term (group) tests the mean difference between both groups. These two tests are not of primary interest. The last term (time $\times$ group) tests whether the time effect is different for the two groups. This is an overall test, however, not specifically testing inter-group differences for postnatal changes with respect to day 0 . Therefore, we present the results of the Wald tests based on the same repeated-measures model, which test whether sampling day changes (postnatal changes or differences with respect to day 0 ) are different for both groups. For these analyses, $P<0.05$ was considered to reflect a significant difference.

For the other fatty acids less sophisticated, more descriptive analyses are presented. Twotailed Mann-Whitney tests were used to compare values at day 0 and changes between day 28 and day 0 for the two study groups. Additionally, the Wilcoxon signed-ranks test was used to evaluate differences between day 28 and day 0 within groups. For these supportive analyses, $P<0.01$ was considered significant.

The volumes of plasma, RBC and intravenous lipids administered in both groups and continuous clinical variables were compared using the two-tailed Mann-Whitney test. Discrete clinical variables were compared using the chi-square test.

\section{RESULTS}

Human milk and artificial formula

The results of the fatty acid analyses of the various formulas and the preterm human milk (average content during the study period) are shown in Table 2. Fatty acids 22:6n-3 and $20: 4 n-6$ were not present in the artificial formulas and only trace amounts of other LCP (preterm formula B) were found. Relative amounts of 22:6n-3, 20:4n-6 and the sums of $n$ 3 and $n-6$ LCP measured in human milk were comparable with those reported in other studies relating to the fatty acid composition of preterm breast milk (Lammi-Keefe \& Jensen, 1984; Carlson et al. 1986).

\section{Plasma phospholipids}

Umbilical blood samples were not available from eight infants in the artificial-formula group and one child in the human-milk group. For three children in the artificial-formula group and the one child in the human-milk group a neonatal sample, taken within $24 \mathrm{~h}$ after birth and before any administration of plasma or $\mathrm{RBC}$, served as a replacement. Despite restrictions placed on birth weight $(<1800 \mathrm{~g})$, three infants in the human-milk group and eight infants in the artificial-formula group were discharged from the neonatal care unit before the 4th week of study. One child in the human-milk group and two in the artificial-formula group were discharged home in good clinical condition after 3 weeks. The other infants were transferred to the neonatal care unit of a non-participating hospital. The pattern of postnatal changes in absolute values for both $22: 6 n-3$ and $20: 4 n-6$ (mg/1 plasma) differed markedly from those for relative fatty acid values (mg/100 mg total fatty acids; Fig. 1). The absolute values for $22: 6 n-3$ and $20: 4 n-6$ increased during the first week of life in both study groups. This increase was followed by a gradual decrease during the next 3 weeks of life. For both $22: 6 n-3$ and $20: 4 n-6$ the absolute postnatal values for the human- 
Table 2. Fatty acid composition ( $\mathrm{mg} / 100 \mathrm{mg}$ total fatty acids) of total lipids of preterm human milk $(H M)$ and preterm and term artificial formula $(A F)$

\begin{tabular}{|c|c|c|c|c|c|c|}
\hline \multirow[b]{3}{*}{ Fatty acid } & \multicolumn{2}{|c|}{$\begin{array}{l}\text { Preterm HM } \\
\quad(\text { ( 11) }\end{array}$} & \multirow{2}{*}{\multicolumn{2}{|c|}{ Preterm AF }} & \multirow{2}{*}{\multicolumn{2}{|c|}{ Term AF }} \\
\hline & & & & & & \\
\hline & Median* & range & A & B & $\mathrm{C}$ & $\mathrm{D}$ \\
\hline$\Sigma \mathrm{SFA} \dagger$ & $44 \cdot 3$ & $41 \cdot 5-49 \cdot 9$ & $53 \cdot 6$ & $54 \cdot 4$ & 54.7 & $45 \cdot 6$ \\
\hline$\Sigma$ MUFA $\dagger$ & $36 \cdot 9$ & $32 \cdot 4-39 \cdot 1$ & 29.2 & $26 \cdot 5$ & $33 \cdot 5$ & $37 \cdot 7$ \\
\hline$\Sigma n-9$ PUFA $\dagger$ & ND & & ND & $0 \cdot 10$ & ND & ND \\
\hline $18: 2 n-6$ & $12 \cdot 2$ & $10 \cdot 8-15 \cdot 2$ & $15 \cdot 6$ & $18 \cdot 1$ & 10.8 & $16 \cdot 3$ \\
\hline $20: 4 n-6$ & 0.58 & $0.48-0.70$ & ND & ND & ND & ND \\
\hline$\sum n-6 \mathrm{LCP} \dagger$ & 1.86 & $1 \cdot 57-2 \cdot 12$ & ND & 0.13 & ND & ND \\
\hline $18: 3 n-3$ & 1.01 & $0.90-1.25$ & $1 \cdot 47$ & 0.62 & 0.77 & $0 \cdot 34$ \\
\hline $22: 6 n-3$ & 0.36 & $0.30-0.44$ & ND & ND & ND & ND \\
\hline$\sum n-3 \mathrm{LCP} \dagger$ & 0.79 & $0.71-0.86$ & ND & 0.16 & ND & ND \\
\hline
\end{tabular}

SFA, saturated fatty acids; MUFA, monounsaturated fatty acids; PUFA, polyunsaturated fatty acids; $\Sigma n-6$ LCP, sum of $n-6$ long-chain polyenes $(20: 2 n-6,20: 3 n-6,20: 4 n-6,22: 2 n-6,22: 4 n-6,22: 5 n-6$ and $24: 2 n-6) ; \Sigma n$ 3 LCP, sum of $n-3$ long-chain polyenes $(20: 3 n-3,20: 4 n-3,20: 5 n-3,22: 3 n-3,22: 5 n-3$ and $22: 6 n-3)$; ND, not detected.

* Median of average content during the study period (day 0-day 28).

+ Measurements were made for individual fatty acids but these are not shown.

milk group were significantly different from those for the formula-fed infants (repeatedmeasures analysis; at day $21 P<0.01$ for $22: 6 n-3$, at day $28 P<0.0005$ for $22: 6 n-3$ and $P<0.05$ for $20: 4 n-6$ ).

Relative values declined steadily and significantly from the 1 st to the 28 th day of life. For $22: 6 n-3$ this decline was $60 \cdot 2 \%$ in the artificial-formula group, which was more than double that in the human-milk group $(23.5 \%)$, reflecting the significant difference between changes in the relative postnatal $22: 6 n-3$ values for the two study groups (repeated-measures analysis; at day $28 P<0.02$ ). The relative amount of $20: 4 n-6$ showed a decline of $53.7 \%$ in the artificial-formula group and $42.9 \%$ in the human-milk group. The relative postnatal 20:4n-6 values were not significantly different in both study groups.

Differences between the absolute and relative changes from birth to the 28 th day of life were also present for the $n-3$ LCP (see Tables 3 and 4 for absolute and relative amounts respectively). The absolute amount for the sum of the $n-3 \mathrm{LCP}(\Sigma n-3 \mathrm{LCP})$ increased from day 0 to day 28 in the human-milk group, whereas it declined in the artificial-formula group. The change in $\Sigma n-3$ LCP (day 28 minus day 0 ) was significantly different for both groups $(P<0 \cdot 01)$. The relative level of $\Sigma n-3$ LCP declined significantly in both study populations. The decrease in the artificial-formula group was significantly larger than that in the human-milk group $(P<0 \cdot 001)$.

Differences between the postnatal changes in absolute and relative values for total $n-6$ LCP ( $\Sigma n-6$ LCP) were similar to those for $\Sigma n-3$ LCP. Changes in $\Sigma n-6$ LCP in the artificial-formula group, however, were not significantly different from those in the infants fed on human milk.

\section{Erythrocyte phospholipids}

The volumes of two RBC samples in the artificial-formula group, one at day 14 and one at day 28 , were too small to guarantee an adequate fatty acid analysis; these samples were discarded. 
(a)

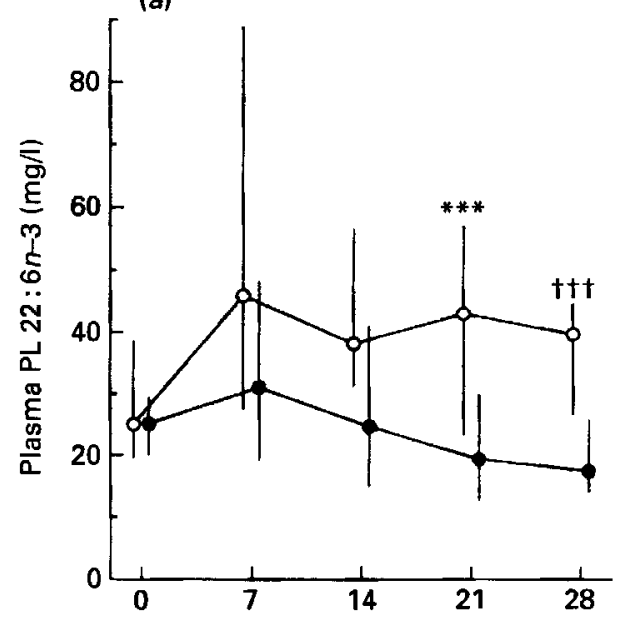

(c)

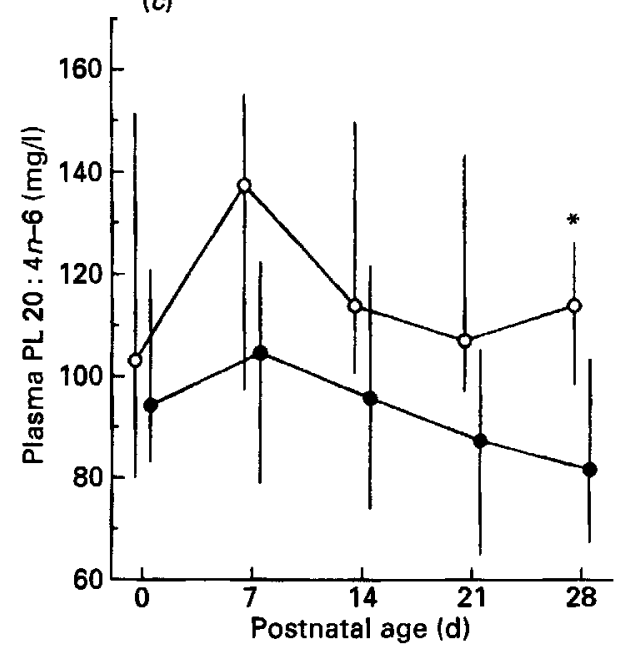

(b)

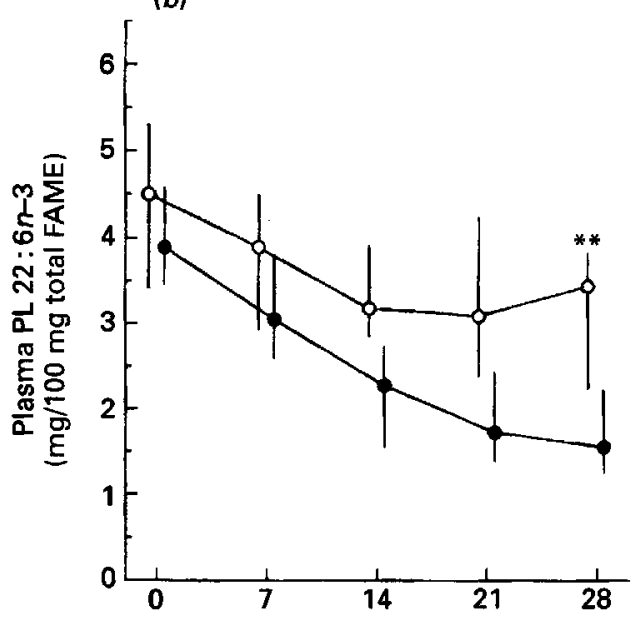

(d)

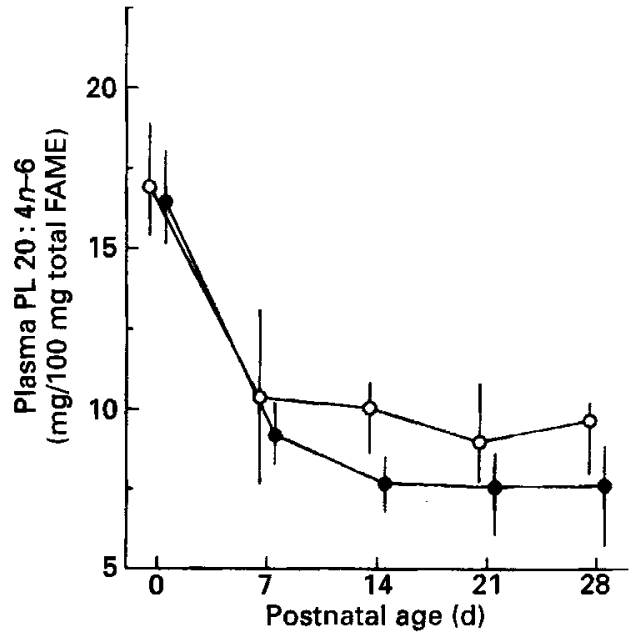

Fig. 1. Fatty acid 22:6n-3 and 20:4n-6 levels in plasma phospholipids (PL) from preterm infants fed on their own mother's milk (HM;O) or on an artificial-formula milk (AF; ) from birth to $28 \mathrm{~d}$ of age expressed as absolute levels $(\mathrm{mg} / 1 ; a, c)$ and as relative levels (mg/100 $\mathrm{mg}$ total fatty acid methyl esters (FAME); $b, d)$. Values are medians and interquartile ranges represented by vertical bars for the following nos. of infants in HM and AF groups respectively: day 012 and 22, day 712 and 26, day 1412 and 26, day 2111 and 25, day 289 and 20. Median values for HM group were significantly different from those for AF group (repeated-measures analysis): ${ }^{*} P<$ $0.05,{ }^{* *} P<0.02,{ }^{* * *} \mathrm{P}<0.01$, $\dagger^{\dagger}+P<0.0005$. For details of subjects and procedures, see Table 1 and pp. 406-410.

The relative and absolute postnatal values for $22: 6 n-3$ and $20: 4 n-6$ showed more or less similar patterns (Fig. 2). Although the postnatal decrease in the formula-fed group was approximately twice the decrease in the human-milk group, the postnatal pattern of changes in both absolute and relative values for $22: 6 n-3$ and $20: 4 n-6$ in the human-milk group were not significantly different from those in the artificial-formula group.

Relative values for $22: 6 n-3$ were significantly lower in the artificial-formula group (Fig. 2, Table $6 ; P<0.05$ ) at birth. No significant differences were found between the absolute fatty acid levels in the RBC PL of both study groups (Table 5). 


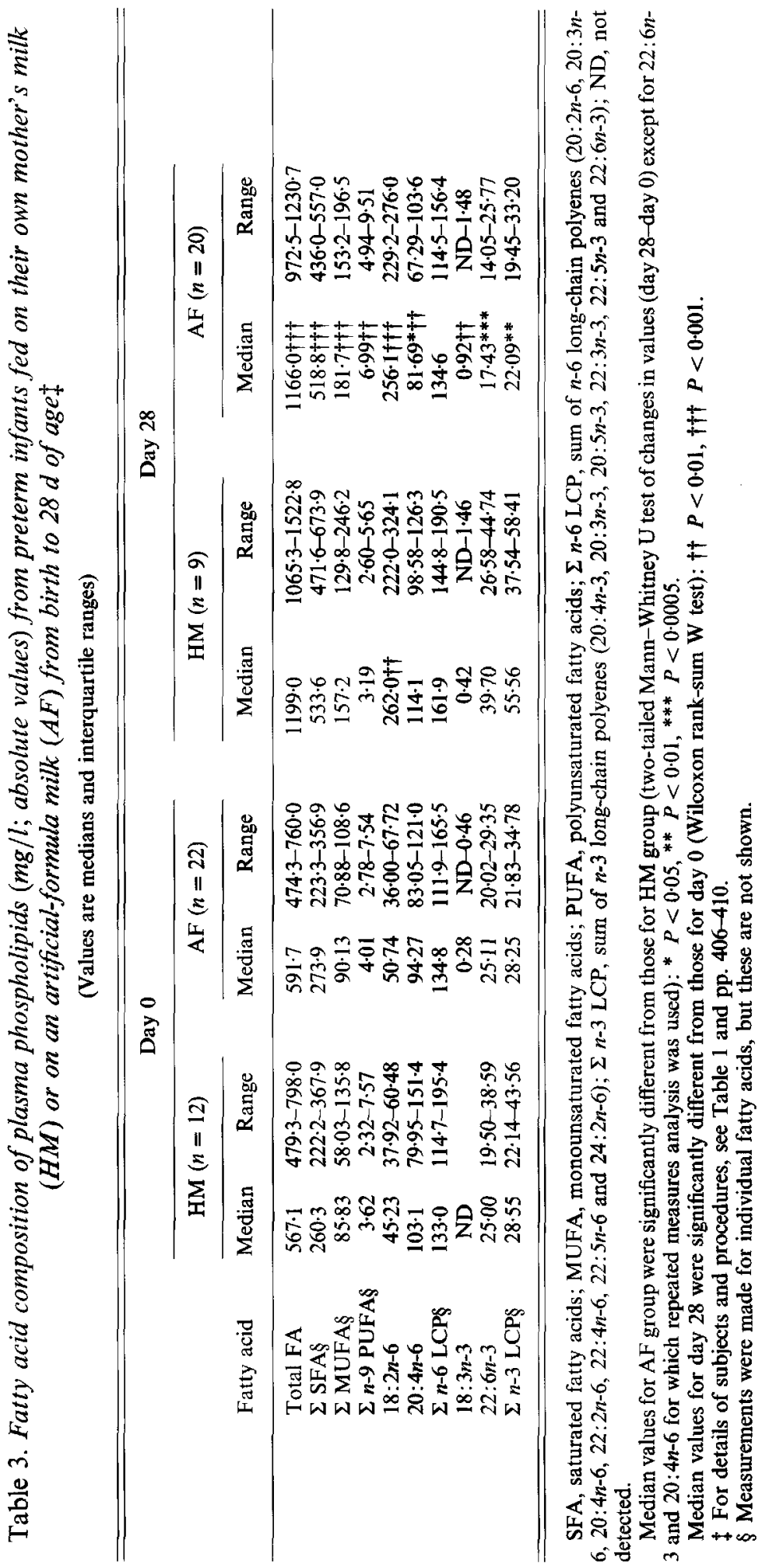




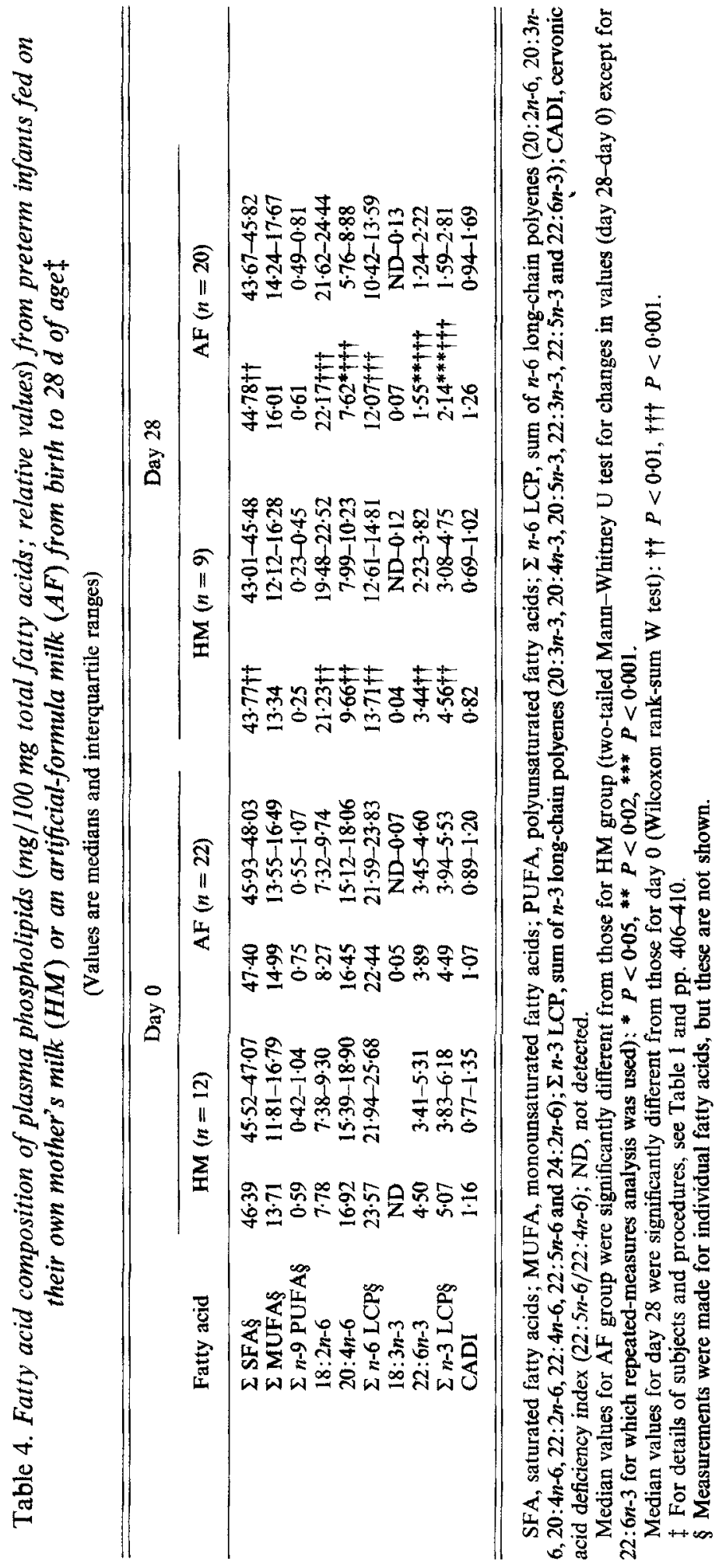


(a)

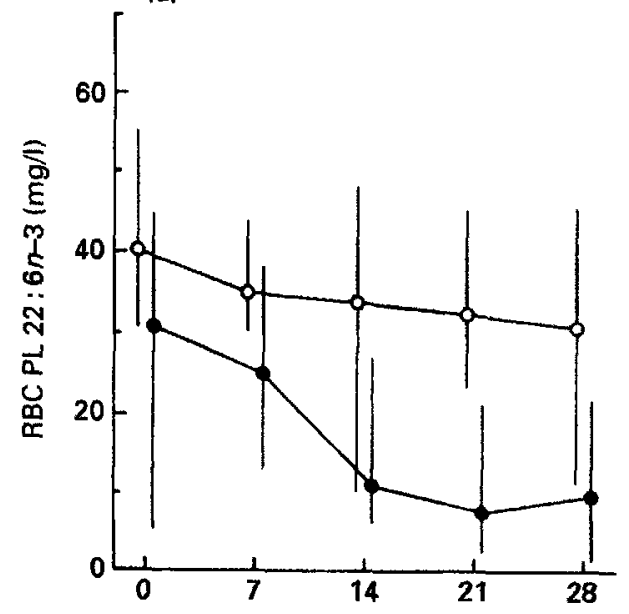

(c)

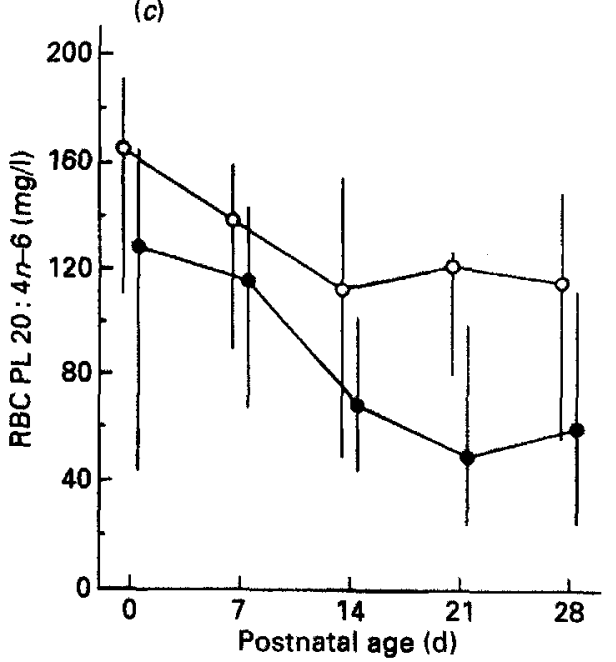

(b)

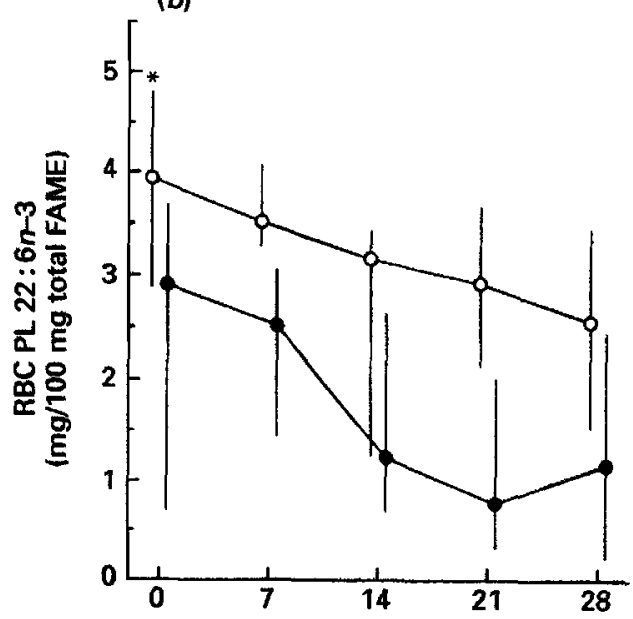

(d)

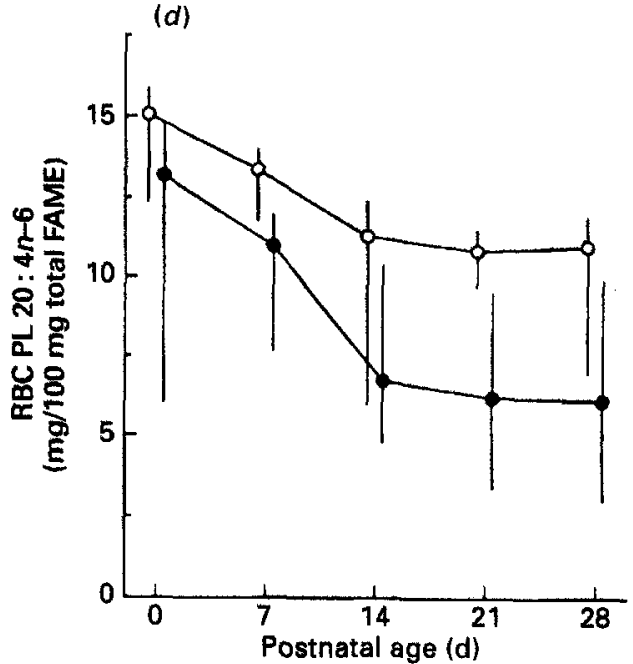

Fig. 2. Fatty acid $22: 6 n-3$ and 20:4n-6 levels in erythrocyte (RBC) phospholipids (PL) from preterm infants fed on their own mother's milk (HM;O) or on an artificial-formula milk (AF; $)$ from birth to $28 \mathrm{~d}$ of age expressed as absolute levels (mg/1;a,c) and as relative levels (mg/100 mg total fatty acid methyl esters (FAME); $b, d$ ). Values are medians and interquartile ranges represented by vertical bars for the following numbers of infants in HM and AF groups respectively: day 012 and 22, day 712 and 26, day 1412 and 25 , day 2111 and 25, day 28 9 and 19. Median values for HM group were significantly different from those for AF group (Mann-Whitney U test): ${ }^{*} P<0.05$. For details of subjects and procedures, see Table 1 and pp. 406-410.

\section{DISCUSSION}

The present study shows that postnatal changes in the LCP status in plasma PL of premature infants, as influenced by the fatty acid composition of their nutritional intake, are different depending on whether it is expressed in terms of absolute fatty acid levels ( $\mathrm{mg} / \mathrm{l})$ or as relative values $(\mathrm{mg} / 100 \mathrm{mg}$ total fatty acids). The absolute values showed an initial increase during the first week of life, followed by a general decline during the following weeks (Fig. 1). Due to an even larger increase in the total amount of PLassociated fatty acids (Fig. 3 and Table 3, values at day 0 were less than half those at days 
章$$
\text { 密 }
$$$$
\text { ذุ }
$$$$
\text { 胥事 }
$$$$
\text { s. }
$$

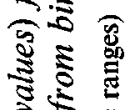$$
\text { 政 }
$$$$
\text { है }
$$$$
\because
$$

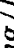$$
\text { So }
$$$$
\text { ปิ }
$$

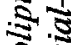

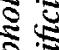$$
\text { ป }
$$$$
\text { 5 }
$$$$
\text { ฐ }
$$$$
\text { 옹 }
$$

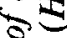$$
\text { : }
$$$$
\text { 范 }
$$$$
\text { క }
$$$$
\text { ปับ }
$$$$
\text { ב }
$$$$
\text { i }
$$$$
\frac{0}{0}
$$

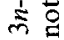

तิ

जิ

के

क्ष

륭며 줄

을

5.

둥

ธิ

i

ㄱำ

है

क्षे

苟

눙

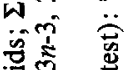

वृ.

造总

행

름도

离

흐을

सक

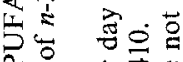

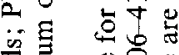

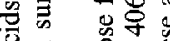

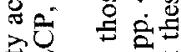

究我

난

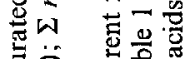

言审

北

혀 굴

을 즘

<응

席

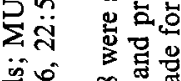

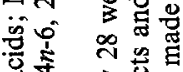

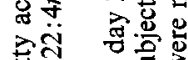

过 0

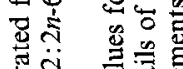

핍 궁

要

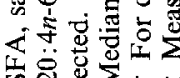
0 - 


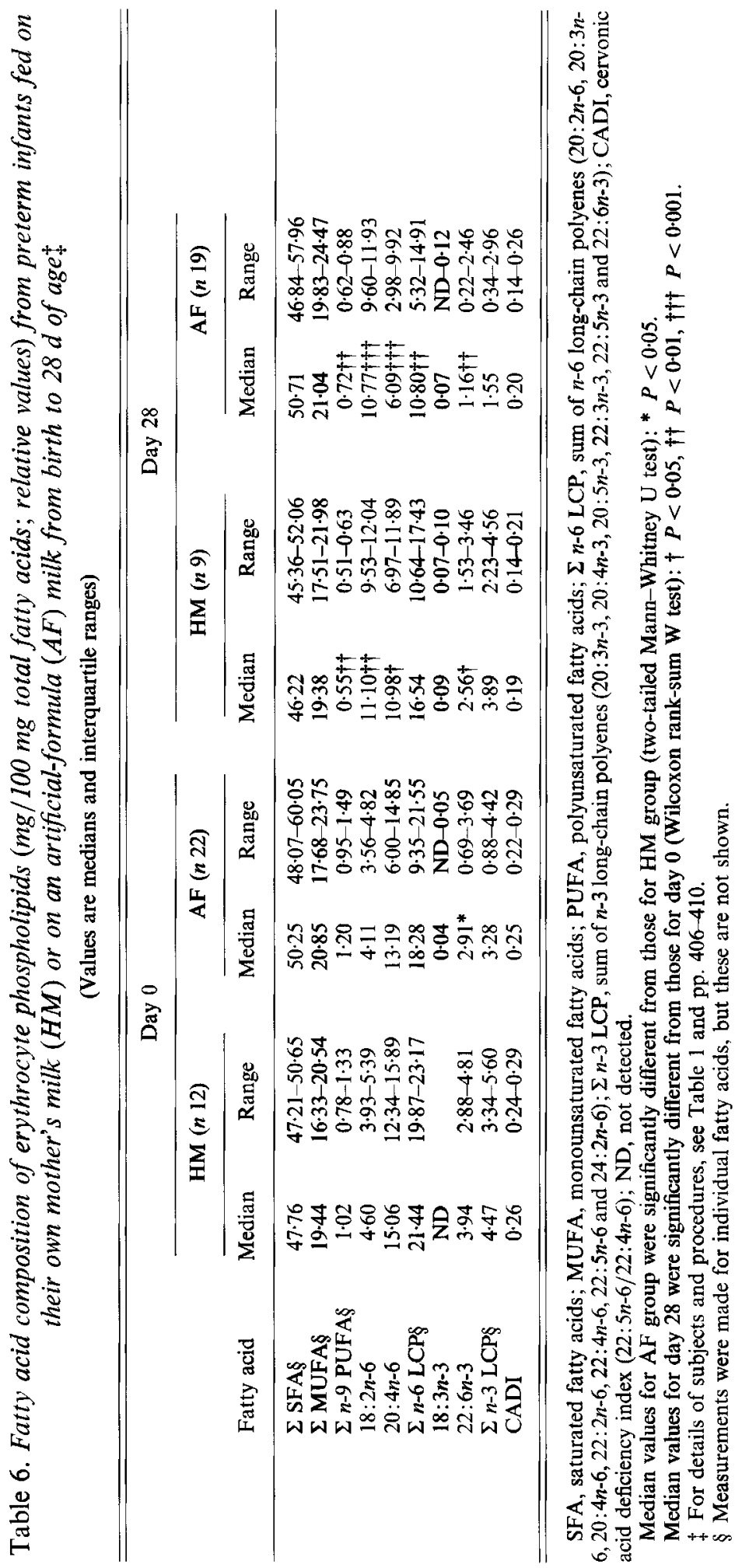


(a)

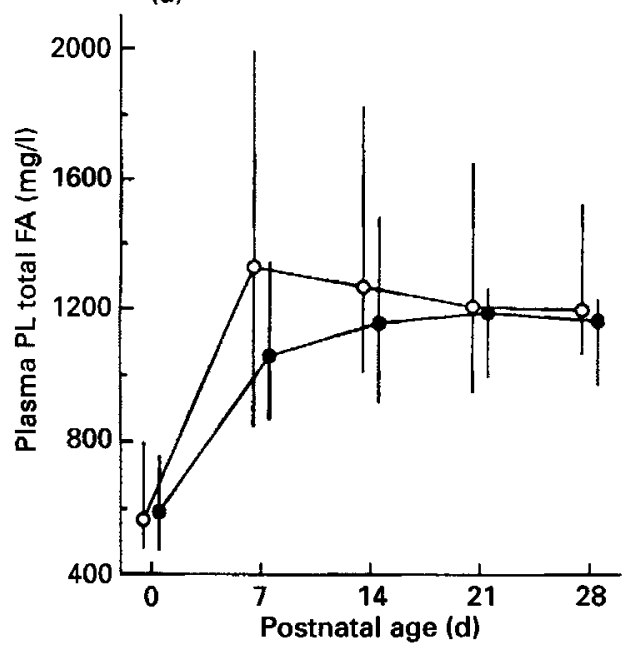

(b)

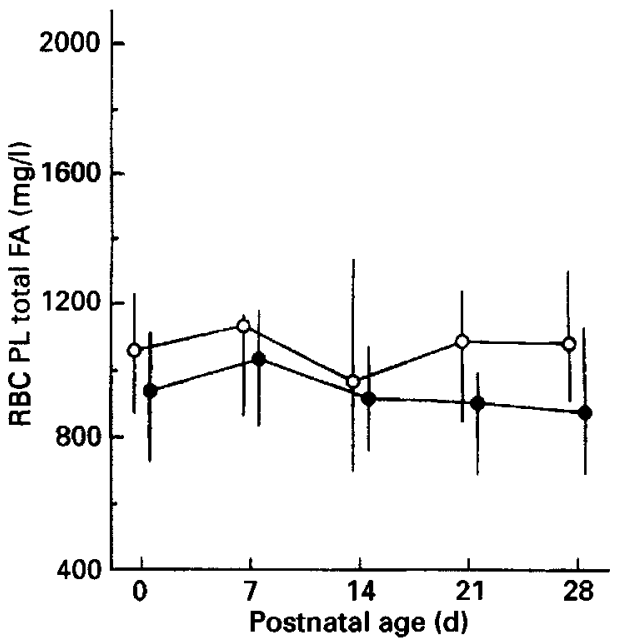

Fig. 3. Total phospholipid (PL)-associated fatty acids (FA; mg/l) in plasma $(a)$ and erythrocytes (RBC; $b)$ from preterm infants fed on their own mother's milk (HM;O) or on an artificial-formula milk (AF; $\bigcirc)$ from birth to $28 \mathrm{~d}$ of age. Values are medians and interquartile ranges represented by vertical bars for the following nos. of infants in HM and AF groups respectively: plasma: day 012 and 22, day 712 and 26, day 1412 and 26 , day 21 11 and 25, day 289 and 20; RBC: day 012 and 22, day 712 and 26, day 1412 and 25 , day 2111 and 25 , day 289 and 19. For details of subjects and procedures, see Table 1 and pp. 406-410.

7 and 28), the initial increase observed for absolute levels of $22: 6 n-3$ and $20: 4 n-6$ did not become apparent when the fatty acid values were expressed as relative values. In RBC PL the total amount of fatty acids present did not change markedly (Fig. 3 and Table 5). As a result, the postnatal changes in absolute and relative values for $22: 6 n-3$ and $20: 4 n-6$ were more or less similar (Fig. 2).

A possible explanation for the observed increase in total plasma PL-associated fatty acids may be the change in nutrient supply which accompanies the transition from fetal life to life outside the uterus. In utero, glucose is the major nutrient, while after birth, fat becomes the main source of energy (Heim, 1983). An increase in the absolute levels of $n$ 3 and $n-6$ LCP of plasma PL within the first days of life was also observed in a group of ten preterm newborn infants (gestational age $<34$ weeks) who received only fat-free parenteral nutrition (Foote et al. 1991). From this finding the author concluded that in the absence of an exogenous lipid source, tissue stores of LCP are released in response to birth. In our study, infants who were unable to tolerate enteral feedings received Intralipid ${ }^{8}$ as an intravenous source of fat as early as the second day of life. This may also explain part of the initial increase in absolute LCP.

Recently, further studies relating to absolute fatty acid concentrations in plasma PL have been published (Clandinin et al. 1992; Carlson et al. 1991, 1992a). The absolute 22:6n-3 and 20:4n-6 levels of our study populations were similar to those reported by Clandinin $e t$ al. (1992) in a study of thirty-four preterm infants receiving their own mother's expressed milk, a conventional formula or a formula containing $n-3$ and $n-6$ LCP. In this study they did not find an increase in plasma PL-associated fatty acids, as observed in our study, possibly because the first blood sample was taken in the first week of life, most probably after this increase had occurred.

Carlson et al. $(1991,1992 a)$ published absolute fatty acid concentrations in plasma phosphatidylethanolamine (PE) and/or phosphatidylcholine (PC), which together ac- 
counted for $>95.0 \%$ of total plasma PL (Carlson et al. 1991). The concentrations (mg/l) of 22:6n-3 and 20:4n-6 in plasma PL of seventy-nine preterm infants receiving either a conventional formula or a formula containing $n-3$ LCP were considerably lower (up to twofold for 22:6n-3 in PC and PE added together) than those reported in our study. This discrepancy may result at least partly from methodological differences. We added the internal standard at the start of the fatty acid analysis, that is before the extraction of total lipids. In this way fatty acid losses during all steps of the analysis were accounted for. Carlson et al. (1991, 1992a), however, added the internal standard (17:0) before the transesterification step. Consequently, fatty acid losses during lipid extraction and separation of the phospholipids were not reflected in the amount of 17:0 FAME detected by GLC. This could result in artefactually lower absolute values for the fatty acids present in the samples. Indeed, the level of total fatty acids present in plasma $\mathrm{PC}$ as reported by Carlson et al. (1992 $a$ ) is approximately half the level of total fatty acids present in plasma total PL in our study. Yet, PC represents approximately $70 \%$ of total plasma PL (Philips \& Dodge, 1967).

Relative amounts of $n-3$ and $n-6$ fatty acids in plasma PL of cord blood reported by Foote et al. (1991) were similar to the amounts measured in our present study. In contrast, the absolute (mg/l) levels of $n-3$ and $n-6$ fatty acids reported were more than ten times lower than those in our study. Detailed information on the timing of the internal standard addition, however, was not given. An overestimation of actual fatty acid amounts in our study seems highly unlikely. Using solid-phase extraction on an aminopropyl-silica column, we are able to separate PL to near homogeneity $(<1.0 \%$ contamination of PL with triacylglyerols and cholesteryl esters, which is in agreement with the value of $1.15 \%$ contamination reported by Kaluzny et al. (1985)).

To our knowledge, no studies relating to absolute fatty acid amounts in RBC PL of preterm infants have been published so far.

In our study we observed significant differences between both the absolute and relative postnatal LCP values in the plasma PL of preterm infants fed on their own mother's breast milk and those of formula-fed preterm infants, with lower LCP levels in the latter group (Fig. 1, Tables 3 and 4). Similar differences were not observed for RBC PL (Fig. 2, Tables 5 and 6). This confirms the findings of recent studies (Carlson et al. 1991; Clandinin et al. 1992) which, over a period of 4 weeks, were unable to demonstrate a significant dietary influence on relative values of $22: 6 n-3$ and $20: 4 n-6$ in RBC PL, but did so in plasma PL and cholesteryl esters. RBC PL are known to have a slower turnover rate than plasma PL, which could result in less-apparent nutritional effects over a relatively short period of time.

The nutritional effect was greater for $22: 6 n-3$ than for $20: 4 n-6$. Effects on $22: 6 n-3$ status were supported by the changes in the sum of the $n-3$ LCP. Moreover, the inter-group difference in the change in the cervonic acid deficiency index (CADI) between birth and the 28th day of life tended to be significant $(P<0 \cdot 05$; significance level for supportive analyses $P<0.01$ ). Because a reduction in the amount of $22: 6 n-3$ is usually compensated by and increased synthesis of $22: 5 n-6$ from $22: 4 n-6$, the ratio between these latter two fatty acids, CADI, is considered a functional variable of the 22:6n-3 status (Holman, 1986; Neuringer et al. 1986). Incidental RBC infusions may have influenced the dietary effect on the LCP status. In our study the average amounts of plasma and RBC received by the artificial-formula group were approximately twice the amounts received by the human-milk group (Table 1). Although this difference was not statistically significant, nonetheless, it may have reduced the difference between the 20:4n-6 (and also the 22:6n-3) status of both study populations. Recently, very-low-birth-weight infants $(<1500 \mathrm{~g})$ receiving more than six blood transfusions during their neonatal course, were shown to maintain higher relative plasma levels of 20:4n-6 (Leaf et al. 1992), which supports the assumption that intravenous RBC and plasma infusions may be an important non-dietary source of LCP. Moreover, 
substantial amounts of $18: 2 n-6$, which can be converted to $20: 4 n-6$, were present in the formulas. Nevertheless, the absolute 20:4n-6 status also showed a significantly larger decrease in the formula-fed infants than in the infants fed on human milk.

All these findings, and those of others (Carlson et al. 1987, 1991; Koletzko et al. 1989; Clandinin et al. 1992), indicate that the conventional artificial formulas are unable to maintain the postnatal LCP status of preterm infants at levels that can be obtained when feeding with preterm human milk. Therefore, to establish comparable $22: 6 n-3$ and $20: 4 n-$ 6 blood levels in formula- and human-milk-fed preterm infants, both $n-3$ and $n-6$ LCP should be added to preterm formula (Uauy, 1990; ESPGAN Committee on Nutrition, 1991). Whether human milk is able to maintain an optimal LCP status in preterm infants remains to be decided. In the present study, in both plasma and RBC PL, relative 22:6n3 and 20:4n-6 levels decreased significantly after birth, in formula-fed infants and also in those raised on human milk. This resulted in values well below those measured in cord blood of infants born after normal full-term pregnancy (Al et al. 1990).

Recently, a number of publications have reported on the influence of the dietary intake of $n-3$ and $n-6$ LCP of preterm infants on several functional and anthropometric variables. The amount of $n-3$ LCP present in the enteral diet was demonstrated to have a significant effect on the function of the retina of very-low-birth-weight newborn infants (Uauy et al. 1990). Infants having no $22: 6 n-3$ in their formula had higher threshold and lower amplitude responses on a rod electroretinogram than those receiving human milk or $n-3$ LCP-supplemented formula. However, the intake of $n-3$ LCP-containing formula was found to be associated with poorer growth in preterm infants (Carlson et al. 1992 b). Furthermore, the 20:4n-6 status in plasma PC was reported to be positively correlated with postnatal growth in preterm infants up to 12 months corrected postnatal age (Carlson et al. 1993). Since $n-3$ LCP supplementation decreases the concentration of plasma $20: 4 n-6$, these findings again support the necessity to add both $n-3$ and $n-6$ LCP in balanced ratios to preterm formula.

In conclusion, the results of the present study emphasize the additional value of the assessment of absolute fatty acid concentrations when studying the dietary effects on the EFA status of preterm infants. Analytical procedures, however, need to be standardized to enable a more effective comparison of results from different research groups. Furthermore, the results obtained warrant further studies of the effects on the postnatal LCP status of adding both $n-3$ and $n-6$ LCP to preterm artificial formulas in amounts comparable with those present in human milk.

The authors gratefully acknowledge the financial support from Nutricia, Zoetermeer, The Netherlands. They also wish to express their appreciation for the help obtained from Mrs J. M. Westdorp, neonatologist (clinical coordination), Mrs M.-J. Slangen, Children's Laboratory of the University Hospital Maastricht (neonatal blood sampling), the nursing personel of the Departments of Neonatology of the University Hospital Maastricht, the Saint Joseph Hospital in Kerkrade and the De Wever Hospital in Heerlen, The Netherlands (practical assistance) and Miss A. van der Zijden (practical assistance).

\section{REFERENCES}

Al, M. D. M., Hornstra, G., van der Schouw, Y. T., Bulstra-Ramakers, M. T. E. W. \& Huisjes, H. J. (1990). Biochemical EFA status of mothers and their neonates after normal pregnancy. Early Human Development 24, $239-248$.

Carlson, S. E., Cooke, R. J., Rhodes, P. G., Peeples, J. M. \& Werkman, S. H. (1992a). Effect of vegetable and marine oils in preterm infant formulas on blood arachidonic and docosahexaenoic acids. Journal of Pediatrics 120, 159-167.

Carlson, S. E., Cooke, R. J., Rhodes, P. G., Peeples, J. M., Werkman, S. H. \& Tolley, E. A. (1991). Long-term 
feeding of formulas high in linolenic acid and marine oil to very low birth weight infants: phospholipid fatty acids. Pediatric Research 30, 404-412.

Carlson, S. E., Cooke, R. J., Werkman, S. H. \& Tolley, E. A. (1992b). First year growth of preterm infants fed standard compared to marine oil n-3 supplemented formula. Lipids 27, 901-907.

Carlson, S. E., Rhodes, P. G. \& Ferguson, M. G. (1986). Docosahexaenoic acid status of preterm infants at birth and following feeding with human milk or formula. American Journal of Clinical Nutrition 44, 798-804.

Carlson, S. E., Rhodes, P. G., Rao, V. S. \& Goldgar, D. E. (1987). Effect of fish-oil supplementation on the n-3 fatty acid content of red blood cell membranes in preterm infants. Pediatric Research 21, 507-510.

Carlson, S. E., Werkman, S. H., Peeples, J. M., Cooke, R. J. \& Tolley, E. A. (1993). Arachidonic acid status correlates with first year growth in preterm infants. Proceedings of the National Academy of Sciences USA 90, 1073-1077.

Chambaz, J., Ravel, D., Manier, M.-C., Pepin, D., Mulliez, N. \& Bereziat, G. (1985). Essential fatty acid interconversion in the human fetal liver. Biology of the Neonate 47, 136-140.

Clandinin, M. T., Chappell, J. E., Heim, T., Swyer, P. R. \& Chance, G. W. (1981). Fatty acid utilization in perinatal de novo synthesis of tissues. Early Human Development 5, 355-366.

Clandinin, M. T., Chappell, J. E., Leong, S., Heim, T., Swyer, P. R. \& Chance, G. W. (1980a). Intrauterine fatty acid accretion rates in human brain: implications for fatty acid requirements. Early Human Development 4, 121-129.

Clandinin, M. T., Chappell, J. E., Leong, S., Heim, T., Swyer, P. R. \& Chance, G. W. (1980b). Extrauterine fatty acid accretion in infant brain : implications for fatty acid requirements. Early Human Development 4, 131-138.

Clandinin, M. T., Parrott, A., Van Aerde, J. E., Hervada, A. R. \& Lien, E. (1992). Feeding preterm infants a formula containing $\mathrm{C}_{20}$ and $\mathrm{C}_{22}$ fatty acids simulates plasma phospholipid fatty acid composition of infants fed human milk. Early Human Development 31, 41-51.

Dallal, G. E. (1988). DESIGN: A Supplementary Module for Systat and Sygraph. Evanston, IL: SYSTAT Inc.

de Jong, A. E. P., van den Berg, T. S., Nijmeijer-Couprie, A., Goedhart, J. P. \& Oosting, E. (1993). Long-term aspects of phospholipidic analysis of fatty acid methyl esters by use of nonpolar capillary gas chromatography. American Journal of Clinical Nutrition 57 Suppl., 813S.

Dixon, W. J., Brown, M. B., Engelman, L. \& Jennrich, R. I. (1990). BMDP Statistical Software Manual: To Accompany the 1990 Software Release, vol. 2. Berkeley: University of California Press.

Dubowitz, L. M. S., Dubowitz, V. \& Goldberg, C. (1970). Clinical assessment of gestational age in the newborn infant. Journal of Pediatrics 77, 1-10.

ESPGAN Committee on Nutrition (1991). Comment on the content and composition of lipids in infant formulas. Acta Padiatrica Scandinavica 80, 887-896.

Fliesler, S. J. \& Anderson, R. E. (1983). Chemistry and metabolism of lipids in the vertebrate retina. Progress in Lipid Research 22, 79-131.

Folch, J., Lees, M. \& Sloane-Stanley, G. H. (1957). A simple method for the isolation and purification of total lipids from animal tissues. Journal of Biological Chemistry 226, 497-509.

Foote, K. D., MacKinnon, M. J. \& Innis, S. M. (1991). Effect of early introduction of formula vs fat-free parenteral nutrition on essential fatty acid status of preterm infants. American Journal of Clinical Nutrition 54, 93-97.

Heim, T. (1983). Energy and lipid requirements of the fetus and preterm infant. Journal of Pediatric Gastroenterology and Nutrition 2, Suppl. 1, 404S-412S.

Holman, R. T. (1960). Ratio of trienoic:tetraenoic acid in tissue lipids as a measure of essential fatty acid requirement. Journal of Nutrition 70, 405-410.

Holman, R. T. (1986). Control of polyunsaturated fatty acids in tissue lipids. Journal of the American College of Nutrition 5, 183-211.

Hornstra, G. (1993). Essential fatty acids, pregnancy and pregnancy complications: a round table discussion. In Essential Fatty Acids and Eicosanoids: Invited Papers From The Third International Congress, pp. 177-182 [A. Sinclair and R. Gibson, editors]. Champaign, Illinois: American Oil Chemists' Society.

Hoving, E. B., Jansen, G., Volmer, M., van Doormaal, J. J. \& Muskiet, F. A. J. (1988). Profiling of plasma triglyceride fatty acids as their methyl esters by capillary gas chromatography, preceded by a rapid aminopropyl silica column chromatographic separation of lipid classes. Journal of Chromatography 434, 395-409.

International Dairy Federation (1987). Milk - Determination of fat content-Röse Gottlieb Gravimetric Method (Reference Method). IDF Standard IC: 1987. Brussels: International Dairy Federation.

Jennrich, R. I. \& Schluchter, M. D. (1986). Unbalanced repeated-measures models with structured covariance matrices. Biometrics 42, 805-820.

Jensen, R. G., Ferris, A. M. \& Lammi-Keefe, C. J. (1992). Lipids in human milk and infant formulas. Annual Review of Nutrition 12, 417-441.

Jensen, R. G., Hagerty, M. M. \& McMahon, K. E. (1978). Lipids of human milk and infant formulas: a review. American Journal of Clinical Nutrition 31, 990-1016.

Kaluzny, M. A., Duncan, L. A., Merritt, M. V. \& Epps, D. E. (1985). Rapid separation of lipid classes in high yield and purity using bonded phase columns. Journal of Lipid Research 26, 135-140.

Kloosterman, G. J. (editor) (1983). Ontwikkelling van embryo tot foetus. In De Voortplanting van de Mens, pp. 7I-75. Bussum, The Netherlands: Uitgeversmaatschappij Centen. 
Koletzko, B., Schmidt, E., Bremer, H. J., Haug, M. \& Harzer, G. (1989). Effects of dietary long chain polyunsaturated fatty acids on the essential fatty acid status of premature infants. European Journal of Pediatrics 148, 669-675.

Lammi-Keefe, C. J. \& Jensen, R. G. (1984). Lipids in human milk: a review. 2: Composition and fat-soluble vitamins. Journal of Pediatric Gastroenterology and Nutrition 3, 172-198.

Leaf, A. A., Leighfield, M. J., Costeloe, K. L. \& Crawford, M. A. (1992). Factors affecting long-chain polyunsaturated fatty acid composition of plasma choline phosphoglycerides in preterm infants. Journal of Pediatric Gastroenterology and Nutrition 14, 300-308.

Morrisson, W. R. \& Smith, L. M. (1964). Preparation of fatty acid methyl esters and dimethylacetals from lipids with borontriffuoride-methanol. Journal of Lipid Research 5, 600-608.

Neuringer, M., Connor, W. E., Lin, D. S., Barstad, L. \& Luck, S. (1986). Biochemical and functional effects of prenatal and postnatal $\omega 3$ fatty acid deficiency on retina and brain in rhesus monkeys. Proceedings of the National Academy of Sciences USA 83, 4021-4025.

Philips, G. B. \& Dodge, J. T. (1967). Composition of phospholipids and phospholipid fatty acids of human plasma. Journal of Lipid Research 8, 676-681.

Pita, M. L., Fernández, M. R., De-Lucchi, C., Medina, A., Martínez-Valverde, A., Uauy, R. \& Gil, A. (1988). Changes in the fatty acids pattern of red blood cell phospholipids induced by type of milk, dietary nucleotide supplementation, and postnatal age in preterm infants. Journal of Pediatric Gastroenterology and Nutrition 7 , $740-747$.

Sastry, P. S. (1985). Lipids of nervous tissue: composition and metabolism. Progress in Lipid Research 24, $69-176$.

Svennerholm, L. (1968). Distribution and fatty acid composition of phosphoglycerides in normal human brain. Journal of Lipid Research 9, 570-579.

Uauy, R. (1990). Are $\omega-3$ fatty acids required for normal eye and brain development in the human? Journal of Pediatric Gastroenterology and Nutrition 11, 296-300.

Uauy, R. D., Birch, D. G., Birch, E. E., Tyson, J. E. \& Hoffman, D. R. (1990). Effect of dietary omega-3 fatty acids on retinal function of very-low-birth-weight neonates. Pediatric Research 28, 485-492.

van der Steege, G., Muskiet, F. A. J., Martini, I. A., Hutter, N. H. \& Boersma, E. R. (1987). Simultaneous quantification of total medium- and long chain fatty acids in human milk by capillary gas chromatography with split injection. Journal of Chromatography 415, 1-11. 